\title{
Purtscher's retinopathy and renal cortical necrosis: two rare vaso-occlusive complications in a patient with acute pancreatitis: a case report
}

Wasim Md. Mohosin UI Haque ${ }^{1 *}$, Mehruba Alam Ananna', Hasna Fahmima Haque², Muhammad Abdur Rahim', Tabassum Samad ${ }^{1}$ and Sarwar lqbal ${ }^{1}$

\begin{abstract}
Background: Purtscher's retinopathy and renal cortical necrosis are two rare vaso-occlusive complications of acute pancreatitis. Purtscher's retinopathy causes sudden impairment of vision, which was first reported in a patient with head trauma. Subsequently, it was also reported as a complication of acute pancreatitis and few other clinical conditions. Acute pancreatitis also rarely causes renal cortical necrosis leading to acute kidney injury. However, the simultaneous presence of both complications is rarely reported.

Case presentation: A 20-year-old Bengali man presented to our hospital with a history of acute upper abdominal pain, vomiting, anuria, and disorientation. He was ultimately found to have bilateral complete blindness due to Purtscher's retinopathy and acute kidney injury due to renal cortical necrosis, as sequelae of acute pancreatitis. He became dialysis-dependent, his vision did not recover, and he died 16 months after diagnosis.

Conclusions: This case highlights Purtscher's retinopathy and renal cortical necrosis might be considered as a recognized pair complication of acute pancreatitis.
\end{abstract}

Keywords: Acute kidney injury, Acute pancreatitis, Blindness, Purtscher's retinopathy, Renal cortical necrosis, Case report

\section{Background}

Purtscher's retinopathy is a rare cause of sudden reduction of vision caused by ischemia involving the posterior pole of one or both eyes. The annual incidence of symptomatic Purtscher's retinopathy is estimated to be 0.24 cases per 1 million population per year [1]. It was first described by Otmar Purtscher in 1910 in a patient with head trauma [2]. Subsequently, a similar retinal clinical picture was found in a few other conditions, including systemic lupus erythematosus, chronic kidney disease, following valsalva maneuver, road traffic accidents with fractured long bone, chest compression, and acute pancreatitis [3-9]. Acute pancreatitis also very rarely causes renal cortical necrosis leading to acute kidney

\footnotetext{
* Correspondence: wmmhaque@live.com

${ }^{1}$ Department of Nephrology and Dialysis, Bangladesh Institute of Research and Rehabilitation in Diabetes, Endocrine and Metabolic Disorders (BIRDEM) General Hospital, Shahbag, Dhaka 1000, Bangladesh

Full list of author information is available at the end of the article
}

injury (AKI) $[10,11]$. Acute cortical necrosis occurs in $1.9-2 \%$ of cases of AKI in developed countries and more frequently $(6-7 \%)$ in developing countries [12]. In most of the cases, it is due to obstetric complications [13-16]. There are some isolated case reports of acute pancreatitis with Purtscher's retinopathy $[4,17-23]$ and acute pancreatitis with renal cortical necrosis [10, 11, 24-29]. To our knowledge, the simultaneous presence of these two conditions is extremely rare; to date, only one case has been reported [25]. In this report, we describe another such case in a patient who presented with sudden bilateral complete blindness due to Purtscher's retinopathy and AKI due to renal cortical necrosis following acute pancreatitis.

\section{Case presentation}

A 20-year-old previously healthy Bengali man presented to our hospital with anuria and features of uremic encephalopathy. Ten days prior to this presentation, he had experienced 
severe upper abdominal pain and vomiting, and he had been treated in a primary care facility for having a case of acute pancreatitis. His initial symptoms improved; however, he gradually became anuric and disoriented. Then he was transferred to our hospital for further management.

At presentation to our hospital, he was severely agitated, restless, and disoriented. He was tachypneic with acidotic breath. Mild pedal edema was present; however, his jugular venous pressure was not raised. His pulse was 112 beats/minute, his blood pressure was 140/90 $\mathrm{mmHg}$, and his body temperature was $98^{\circ} \mathrm{F}$. Signs of meningeal irritation were absent, and his plantar response was bilaterally extensor. His fundus could not be evaluated, and examination of his other systems was unremarkable.

His laboratory parameters showed features of renal dysfunction (serum creatinine $13 \mathrm{mg} / \mathrm{dl}$, serum urea $293 \mathrm{mg} / \mathrm{dl}$ ), raised pancreatic enzymes (serum amylase $249 \mathrm{U} / \mathrm{L}$ [reference up to $100 \mathrm{U} / \mathrm{L}$ ], serum lipase $227 \mathrm{U} / \mathrm{L}$ [reference 13-60 U/L), normal liver function tests (serum bilirubin $0.9 \mathrm{mg} / \mathrm{dl}$, alanine aminotransferase $38 \mathrm{U} / \mathrm{L}$, aspartate aminotransferase $35 \mathrm{U} / \mathrm{L}$, alkaline phosphatase $122 \mathrm{U} / \mathrm{L}$, serum albumin $37 \mathrm{~g} / \mathrm{L}$ ), normal potassium (5.1 mmol/L), normal bicarbonate $(19 \mathrm{mmol} / \mathrm{L})$, and normal triglycerides $(173 \mathrm{mg} / \mathrm{dl})$. His serological markers, including antinuclear antibodies, cytoplasmic antineutrophil cytoplasmic antibodies, perinuclear antineutrophil cytoplasmic antibodies, C3, and C4, were within normal limits. An ultrasonogram of his whole abdomen was unremarkable, but non-contrast-enhanced computed tomography (CT) findings were suggestive of acute pancreatitis (Fig. 1). His kidneys were unremarkable, however.

The patient was managed as having a case of AKI and acute pancreatitis. Urgent hemodialysis was initiated. After he had received two sessions of hemodialysis, his

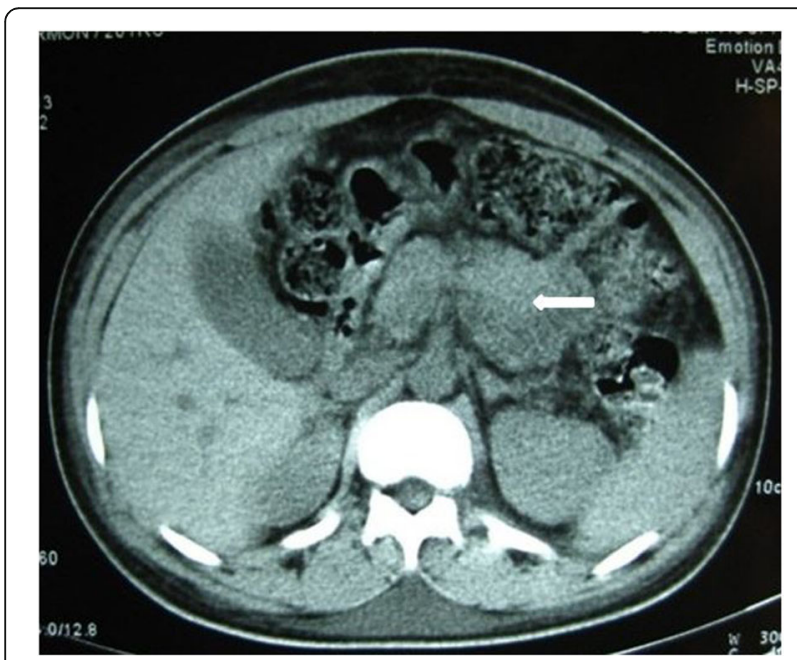

Fig. 1 Non-contrast-enhanced computed tomography of the patient's abdomen shows swollen pancreas (white arrow) with peripancreatic edema suggestive of acute pancreatitis level of consciousness improved, but he complained of profound visual loss. An assessment revealed only perception of light. A funduscopic examination showed retinal whitening and extensive cotton wool exudates as well as Purtscher's flecken (Fig. 2) compatible with Purtscher's retinopathy. High-dose parenteral methylprednisolone ( $1 \mathrm{~g}$ intravenously once daily for 3 days) was administered. For evaluation of renal dysfunction, a renal biopsy was done; the histopathological findings were compatible with renal cortical necrosis (Fig. 3).

The patient denied substance abuse or alcohol ingestion. He did not consume any nephrotoxic drugs or herbal products in the recent past. No history suggesting connective tissue diseases was available, nor did he have a history of hypotension throughout the course of his current illness.

The patient was finally diagnosed with acute pancreatitis complicated with renal cortical necrosis leading to AKI and Purtscher's retinopathy leading to complete bilateral blindness. He died 16 months after his initial presentation as a result of a recurrent attack of acute pancreatitis. Before that, he had been undergoing maintenance hemodialysis; however, his renal function did not recover, though his vision was improved to fingercounting at 2 feet.

\section{Discussion}

Acute pancreatitis in most cases presents in a milder form with prompt recovery. However, in about $20 \%$ of cases, it can present in severe form with local and systemic complications. Acute pancreatitis rarely leads to Purtscher's retinopathy and renal cortical necrosis [4, 17-23]. Though several mechanisms are described, both can be caused by a common phenomenon, which might have occurred in our patient. The presence of pancreatic proteases in the systemic circulation following acute pancreatitis is the inciting factor. Subsequently, activation of complement cascade leads to the formation of C5a-induced leukocyte, platelet, and fibrin aggregation. This ultimately causes retinal and renal cortical embolization and ischemia, leading to life- and organthreatening complications, as in our patient [21-23, 30-32]. Endothelin released from damaged vessels also contributes to this process by producing vasospasm, which further aggravates ischemia.

Association of Purtscher's retinopathy with acute pancreatitis was first described by Inkeles and Walsh in 1975 [4]. Purtscher's retinopathy clinically manifests as no visual impairment to a varying degree of visual impairment, which in many cases improves spontaneously with time [33]. This retinopathy is characterized by the presence of cotton wool spots and flame-shaped hemorrhages located only in the end arteriolar retinal circulation around the disc and macula, described in 


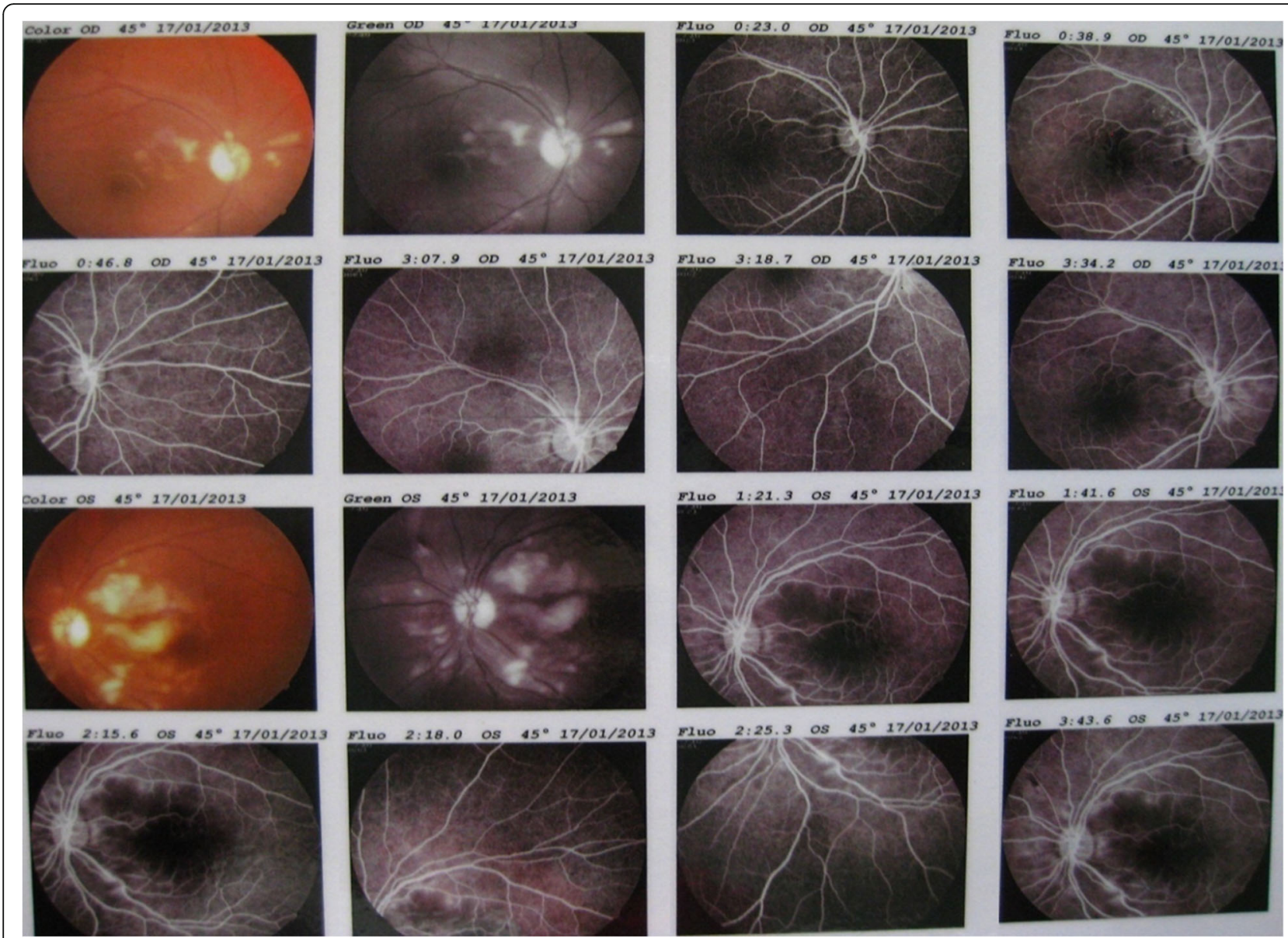

Fig. 2 Fundus photographs of both eyes show cotton wool spots at the posterior pole and peripapillary areas. Fluorescein fundus angiography of both eyes (early, middle, and late phases) shows an increased foveal avascular area and a capillary dropout area at the posterior pole

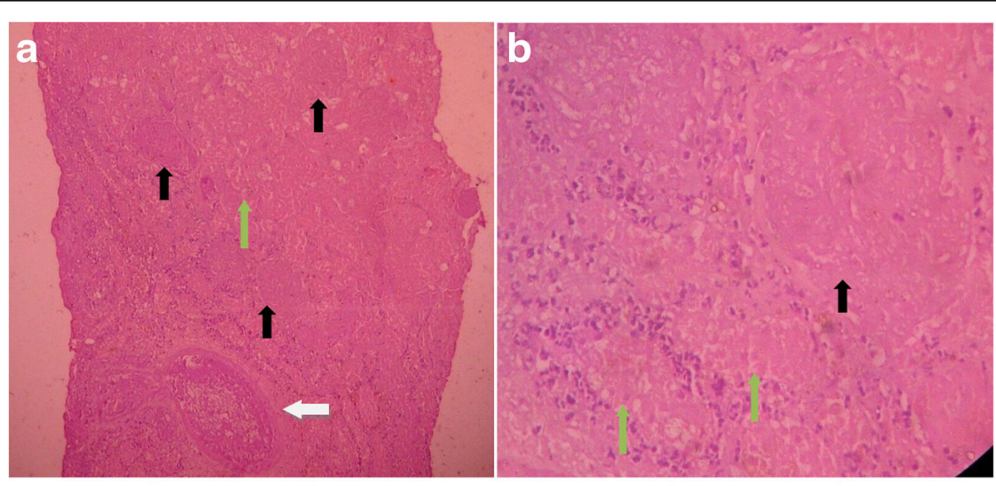

(Low power view)
(High power view)

Fig. 3 Hematoxylin and eosin-stained sections from core biopsy reveal renal cortex containing few glomeruli and expected number of renal tubules. Glomeruli (black arrows in $\mathbf{a}$ and $\mathbf{b}$ ) and tubules (green arrows in $\mathbf{a}$ and $\mathbf{b}$ ) show extensive coagulation necrosis, with few of the tubular cells having karyolytic nuclei. No viable glomerulus or tubule is discernible; however, the connective tissue framework is preserved. Sections also reveal necrosed blood vessels, including a necrosed and thrombosed intralobular artery (white arrow in $\mathbf{a}$ ). Neutrophilic infiltrates are also present in the interstitium surrounding necrosed glomeruli and tubules 
83-92\% of a series of cases [34]. Purtscher flecken (intraretinal whitening with a clear zone on either side of the retinal arterioles, venules, and precapillary arterioles) are considered to be pathognomonic, but it occurs in only $50 \%$ of cases [34]. All of the above-mentioned funduscopic findings were present in our patient (Fig. 2). The outcome of Purtscher's retinopathy is uncertain; however, in most of the cases, visual acuity improves with time [33, 35]. Resolution of retinal lesions is expected within about 4 months. Male sex and pancreatitis as a cause are usually associated with good prognosis [33]; unfortunately, our patient's visual acuity did not improve significantly. Considering the beneficial effect of high-dose steroid treatment, as documented in a few case reports [36, 37], we administered intravenous methylprednisolone for 3 consecutive days, which appeared to be ineffective as observed in many other cases [1,33, 34].

Renal cortical necrosis is an extremely rare complication of acute pancreatitis [10, 11, 24-29]. The lesion is irreversible, leading to total loss of kidney function and end-stage renal disease in severe cases. Anuria is the usual presenting symptom of acute renal cortical necrosis. Prolonged anuria ( $>4$ weeks) in appropriate clinical settings suggests the clinical diagnosis of renal cortical necrosis [12]. Renal hypoperfusion resulting from prolonged shock and direct or indirect endothelial injury can cause renal cortical necrosis. In acute pancreatitis other than hypovolemic shock, the presence of proteolytic enzymes in the systemic circulation indirectly causes endothelial injury and severe spasm of renal microcirculation, leading to diffuse ischemic necrosis of the cortical structures, such as vessels, tubules, and glomeruli [10-12]. In our patient, renal histopathology showed extensive coagulative necrosis of all the cortical structures, including glomeruli, tubules, and vessels (Fig. 3). The tissue from the medulla was viable. Direct immunofluorescence showed no deposition. Though histopathology is the gold standard in diagnosing renal cortical necrosis, it can often be reliably replaced by contrast-enhanced CT. Low attenuation of cortex spearing thin rim of subcapsular cortex and medulla on contrast-enhanced CT scans is a characteristic finding in renal cortical necrosis; however, to minimize the further risk of kidney damage in our patient, we did not perform contrast-enhanced CT [38, 39]. Slater et al. described a case of acute pancreatitis complicated with Purtscher's retinopathy and renal cortical necrosis, similar to our patient's case [25]. Their patient had no visual impairment; his renal function improved gradually over time; and by 2 years he became dialysis-free. His biopsy showed renal cortical necrosis with patent vessels; however, in our patient, the vessels were also involved in the necrotic process, indicating more extensive damage. Our patient's fatal outcome may imply the severity of his disease.

Renal outcome in renal cortical necrosis depends on the severity of damage. In patchy lesions, renal function usually recovers, but in cases with diffuse involvement, end-stage renal disease is the norm [12]. However, in certain cases, there may be a slow rise in creatinine clearance, and a gradual gain in renal function has been observed over 1-2 years. The glomerular filtration rate may reach a final plateau level of approximately $20-24 \mathrm{ml} /$ minute [40, 41]. Our patient's renal impairment did not recover even 16 months after the onset of illness, which might be due to the extensive nature of the damage.

\section{Conclusions}

Because of the paucity of cases, widely accepted, uniform management guidelines for treating Purtscher's retinopathy and renal cortical necrosis complicating acute pancreatitis are lacking. Cases have been managed in different ways; however, improvement of visual acuity in Purtscher's retinopathy and partial improvement of renal function in acute cortical necrosis with time are not uncommon. In our patient, the outcome was fatal, which might have been due to the severity of his disease. Though rare, simultaneous occurrence of Purtscher's retinopathy and renal cortical necrosis might be considered as a recognized paired complication of acute pancreatitis.

Abbreviations
AKI: Acute kidney injury; CT: Computed tomography

\section{Acknowledgements}

The authors acknowledge Dr. Md. Abdur Rakib, MBBS, DO, FCPS, Assistant Professor, Department of Ophthalmology, BIRDEM General Hospital for reviewing fundus photographs and Fluorescein fundus angiography.

Funding

Not applicable.

Availability of data and materials Not applicable.

\section{Authors' contributions}

WMMUH managed the patient and also did the literature review and manuscript preparation. MAA did the literature search and drafted the manuscript. HFH managed the patient, did the literature review, and drafted the manuscript. MAR did the literature search and edited the draft of the manuscript. TS did the literature search and made critical intellectual contributions to the draft of the manuscript. SI was involved in decision making in treating the patient and in editing the draft of the manuscript. All authors read and approved the final manuscript.

\section{Competing interests}

The authors declare that they have no competing interests.

\section{Consent for publication}

Written informed consent was obtained from the patient's next of kin for publication of this case report and any accompanying images. A copy of the written consent is available for review by the Editor-in-Chief of this journal.

Ethics approval and consent to participate

Not applicable.

\section{Author details}

'Department of Nephrology and Dialysis, Bangladesh Institute of Research and Rehabilitation in Diabetes, Endocrine and Metabolic Disorders (BIRDEM) General Hospital, Shahbag, Dhaka 1000, Bangladesh. ${ }^{2}$ Department of Internal Medicine, Bangladesh Institute of Research and Rehabilitation in Diabetes, 
Endocrine and Metabolic Disorders (BIRDEM) General Hospital, Shahbag, Dhaka 1000, Bangladesh.

\section{Received: 21 August 2016 Accepted: 21 October 2016 Published online: 15 November 2016}

\section{References}

1. Agrawal A, McKibbin M. Purtscher's retinopathy: epidemiology, clinical features and outcome. Br J Ophthalmol. 2007:91(11):1456-9.

2. Purtscher O. Unknown findings after head trauma [in German]. Ber Zusammenkunft Dtsch Ophthalmol Ges. 1910:36:294-301.

3. Tabandeh H, Rosenfeld PJ, Alexandrakis G, Kronish JP, Chaudhry NA. Purtscher-like retinopathy associated with pancreatic adenocarcinoma. Am J Ophthalmol. 1999;128(5):650-2.

4. Inkeles DM, Walsh JB. Retinal fat emboli as sequela to acute pancreatitis. Am J Ophthalmol. 1975;80(5):935-8.

5. Lauer AK, Klein ML, Kovarik WD, Palmer EA. Hemolytic uremic syndrome associated with Purtscher-like retinopathy. Arch Ophthalmol. 1998;116(8): 1119-20.

6. Zwolinska D, Medynska A, Galar A, Turno A. Purtscher-like retinopathy in nephrotic syndrome associated with mild chronic renal failure. Pediatr Nephrol. 2000;15(1-2):82-4.

7. Sellami D, Ben Zina Z, Jelliti B, Abid D, Feki J, Chaâbouni M. Purtscher-like retinopathy in systemic lupus erythematosus: two cases [in French]. J Fr Ophtalmol. 2002;25(1):52-5.

8. Nor-Masniwati S, Azhany Y, Zunaina E. Purtscher-like retinopathy following valsalva maneuver effect: case report. J Med Case Rep. 2011;5:338.

9. Mayer C, Khoramnia R. Purtscher-like retinopathy caused by acute pancreatitis. Lancet. 2011;378(9803):1653.

10. Krishna GS, Kishore KC, Sriram NP, Sainaresh W, Lakshmi AY, Siva KV. Bilateral renal cortical necrosis in acute pancreatitis. Indian J Nephrol. 2009;19(3):125

11. Alfonzo AV, Fox JG, Imrie CW, Roditi G, Young B. Acute renal cortical necrosis in a series of young men with severe acute pancreatitis. Clin Nephrol. 2006;66(4):223-31.

12. Prakash J, Singh VP. Changing picture of renal cortical necrosis in acute kidney injury in developing country. World J Nephrol. 2015:4(5):480-6.

13. Prakash J, Vohra R, Wani IA, Murthy AS, Srivastva PK, Tripathi K, et al. Decreasing incidence of renal cortical necrosis in patients with acute renal failure in developing countries: a single-centre experience of 22 years from Eastern India. Nephrol Dial Transplant. 2007;22(4):1213-7.

14. Grünfeld JP, Ganeval D, Bournérias F. Acute renal failure in pregnancy. Kidney Int. 1980:18(2):179-91.

15. Chugh KS, Jha V, Sakhuja V, Joshi K. Acute renal cortical necrosis - a study of 113 patients. Ren Fail. 1994;16(1):37-47.

16. Prakash J, Tripathi K, Pandey LK, Sahai S, Usha, Srivastava PK. Spectrum of renal cortical necrosis in acute renal failure in eastern India. Postgrad Med J. 1995;71(834):208-10

17. Jeon SY, Jung E, Seol HJ, Hur YJ. Development of Purtscher-like retinopathy after pre-eclampsia combined with acute pancreatitis. Obstet Gynecol Sci. 2013;56(4):261-4.

18. Stefanicková J, Hasa J, Hlinstáková S, Pesko K, Krahulec B, Strmen P. Purtscher-like retinopathy in acute alcoholic pancreatitis: fluorescein angiography and optical coherence tomography findings [in Slovak]. Cesk Slov Oftalmol. 2010;66(4):165-9.

19. Krahulec B, Stefanicková J, Hlinstáková S, Hirnerová E, Kosmálová V, Hasa J, et al. Purtscher-like retinopathy - a rare complication of acute pancreatitis [in Slovak]. Vnitr Lek. 2008:54(3):276-81.

20. López-Tizón E, Reinoso-Montalvo C, Mencía-Gutiérrez E, Gutiérrez-Díaz E. Acute pancreatitis presenting as sudden blindness [in Spanish]. Arch Soc Esp Oftalmol. 2006;81(3):161-3.

21. Carrera CR, Pierre LM, Medina FM, Pierre-Filho PT. Purtscher-like retinopathy associated with acute pancreatitis. Sao Paulo Med J. 2005;123(6):289-91.

22. Campo SM, Gasparri V, Catarinelli G, Sepe M. Acute pancreatitis with Purtscher's retinopathy: case report and review of the literature. Dig Liver Dis. 2000;32(8):729-32.

23. Jacob HS, Goldstein IM, Shapiro I, Craddock PR, Hammerschmidt DE, Weissmann G. Sudden blindness in acute pancreatitis: possible role of complement-induced retinal leukoembolization. Arch Intern Med. 1981;141(1):134-6.
24. Fox JG, Sutcliffe NP, Boulton-Jones JM, Imrie CW. Acute pancreatitis and renal cortical necrosis. Nephrol Dial Transplant. 1990:5(7):542-4.

25. Slater G, Goldblum SE, Tzamaloukas AH, Jones WL, Goldhahn RT. Renal cortical necrosis and Purtscher's retinopathy in hemorrhagic pancreatitis. Am J Med Sci. 1984;288(1):37-9.

26. Richet G, de Montera, Ducrot G, Ducroiset B, Vassalli P. Cortical necrosis and renal insufficiency in acute pancreatitis [in French]. Acta Chir Acad Sci Hung. 1961;2:201-14.

27. Richet G, de Montera, Ducrot H, Ducroiset B, Vassalli P. Cortical necrosis and renal insufficiency in the course of acute pancreatitis. I. Clinical aspects and anatomo-pathology [in French]. Presse Med. 1960;68:2275-7.

28. Richet G, de Montera, Ducrot H, Ducroiset B, Vassalli P. Cortical necrosis and renal insufficiency during acute pancreatitis. II. Mechanism of the renal attack and the place of pancreatitis among the causes of renal insufficiency [in French]. Presse Med. 1960:68:2332-4.

29. Dolman CL, Herd JA. Acute pancreatitis in pregnancy complicated by renal cortical necrosis and cerebral mucormycosis. Can Med Assoc J. 1959:81:562-4.

30. Holak H, Holak N, Huzarska M, Holak S. Pathogenesis of Purtscher's retinopathy and Purtscher-like retinopathy [in Polish]. Klin Oczna. 2007; 109(1-3):38-45.

31. Kincaid MC, Green WR, Knox DL, Mohler C. A clinicopathological case report of retinopathy of pancreatitis. Br J Ophthalmol. 1982:66(4):219-26.

32. Gullick HD. Increased plasma proteolytic activity due to arginine amidase in patients with pancreatitis. N Engl J Med. 1963;268(16):851-7.

33. Miguel Al, Henriques F, Azevedo LF, Loureiro AJ, Maberley DA. Systematic review of Purtscher's and Purtscher-like retinopathies. Eye (Lond). 2013;27(1):1-13.

34. Proença Pina J, Ssi-Yan-Kai K, de Monchy I, Charpentier B, Offret H, Labetoulle M. Purtscher-like retinopathy: case report and review of the literature [in French]. J Fr Ophtalmol. 2008;31 (6 Pt 1):609-13.

35. Massa R, Vale C, Macedo M, Furtado MJ, Gomes M, Lume M, et al. Purtscherlike retinopathy. Case Rep Ophthalmol Med. 2015;2015:421329.

36. Wang AG, Yen MY, Liu JH. Pathogenesis and neuroprotective treatment in Purtscher's retinopathy. Jpn J Ophthalmol. 1998:42(4):318-22.

37. Atabay C, Kansu T, Nurlu G. Late visual recovery after intravenous methylprednisolone treatment of Purtscher's retinopathy. Ann Ophthalmol. 1993;25(9):330-3.

38. Kim HJ, Cho OK. CT scan as an important diagnostic tool in the initial phase of diffuse bilateral renal cortical necrosis. Clin Nephrol. 1996;45(2):125-30.

39. Jordan J, Low R, Jeffrey Jr RB. CT findings in acute renal cortical necrosis. J Comput Assist Tomogr. 1990;14(1):155-6.

40. Effersoe P, Raaschou F, Thomsen AC. Bilateral renal cortical necrosis: a patient followed up over eight years. Am J Med. 1962;33:455-8.

41. Rieselbach RE, Klahr S, Bricker NS. Diffuse bilateral cortical necrosis; a longitudinal study of the functional characteristics of residual nephrons. Am J Med. 1967:42(3):457-68.

\section{Submit your next manuscript to BioMed Central and we will help you at every step:}

- We accept pre-submission inquiries

- Our selector tool helps you to find the most relevant journal

- We provide round the clock customer support

- Convenient online submission

- Thorough peer review

- Inclusion in PubMed and all major indexing services

- Maximum visibility for your research

Submit your manuscript at www.biomedcentral.com/submit
) Biomed Central 